\title{
LOST HOPES AND MIXED QUOTES
}

\author{
Savas L. Tsohatzidis \\ Aristotle University of Thessaloniki
}

\begin{abstract}
The analysis of mixed quotation proposed in Cappelen \& Lepore (1997a), purportedly as a development of Davidson's accounts of direct and of indirect quotation, is critically examined. It is argued that the analysis fails to specify either necessary or sufficient conditions on mixed quotation, and that the way it has been defended by its proponents makes its alleged Davidsonian parentage questionable.
\end{abstract}

\section{Introduction}

In Cappelen \& Lepore (1997a), Herman Cappelen and Ernie Lepore (hereafter, C\&L) propose an analysis of sentences like (1), which they describe as instances of 'mixed quotation' - a variety of quotation that, according to them, is semantically distinct from, though in certain semantically significant ways related to, the more familiar varieties of direct and of indirect quotation, exemplified by sentences like (2) and (3), respectively:

(1) Alice said that life "is difficult to understand".

(2) Alice said "Life is difficult to understand".

(3) Alice said that life is difficult to understand.

The analysis of mixed quotation that $\mathrm{C} \& \mathrm{~L}$ propose consists in combining elements deriving, on the one hand, from a certain independently available analysis of indirect quotation and, on the other hand, from a certain independently available analysis of direct question. As far as indirect quotation is concerned, C\&L adopt the Davidsonian analysis in terms of the notion of samesaying (cf. Davidson 1968). On that analysis, a statement that indirectly quotes a certain speaker is equivalent to a statement where the quoted speaker is claimed to have produced an utterance that stands in the samesaying relation to an utterance demonstratively referred to by the quoting speaker; thus, the semantic representation of an indirect quotation like (3) is (3-D), where "SS" stands for the samesaying relation:

(3-D) $\exists u(\operatorname{Said}(\mathrm{a}, u) \& \mathrm{SS}(u$, that)). Life is difficult to understand 
As far as direct quotation is concerned, C\&L adopt a Davidsonian analysis (cf. Davidson 1979) which they formulate in terms of the notion of sametokening. On that analysis, a statement that directly quotes a certain speaker is equivalent to a statement where the quoted speaker is claimed to have produced an utterance that stands in the sametokening relation to an utterance demonstratively referred to by the quoting speaker; thus, the semantic representation of a direct quotation like (2) is (2-D), where "ST" stands for the sametokening relation:

(2-D) $\exists u(\operatorname{Said}(\mathrm{a}, u) \& \mathrm{ST}(u$, these)). Life is difficult to understand

Turning then to the analysis of statements involving what they call 'mixed quotation', C\&L propose that such statements should be analyzed as equivalent to statements where the quoted speaker is claimed to have produced an utterance that, on the one hand, samesays, and, on the other hand, at least partly sametokens, an utterance demonstratively referred to by the quoting speaker; thus, the correct analysis of a mixed quotation like (1) would, according to C\&L, be the one in (1-D), where "SS" stands for the samesaying and "ST" for the sametokening relation:

(1-D) $\exists u(\operatorname{Said}(\mathrm{a}, u) \& \mathrm{SS}(u$, that $) \& \mathrm{ST}(u$, these)). Life is difficult to understand

In Tsohatzidis (1998) I have called C\&L's proposal "the hybrid theory of mixed quotation", and argued that it fails to specify necessary conditions for mixed quotation, first because there are mixed quotations with respect to which the sametokening clause of C\&L's analysis is not satisfied (even though the samesaying clause might be), and secondly because there are mixed quotations with respect to which the samesaying clause of C\&L's analysis is not satisfied (even though the sametokening clause might be). My purpose in this paper is (a) to briefly rehearse these arguments, which I still regard as compelling, (b) to show why C\&L's subsequent attempt to neutralize these arguments has failed, and (c) to present two additional arguments against the hybrid theory, of which the first shows that there are mixed quotations with respect to which the samesaying and sametokening clauses of C\&L's analysis simultaneously fail to be satisfied, and the second complements the previous ones by questioning not the alleged necessity of the samesaying and the sametokening clauses, but rather their alleged sufficiency. 


\section{The sametokening problem}

The first of the two arguments presented in Tsohatzidis (1998) shows that there are instances of mixed question that, though they may be taken to satisfy the samesaying clause of C\&L's analysis, cannot be supposed to satisfy the sametokening clause. Consider the sentences in (4) and (5), which would be taken to accurately reflect certain views that Descartes and Frege respectively held, and to express, therefore, true claims about their respective opinions:

(4) Descartes said that man "is a thinking substance".

(5) Frege said that predicate expressions "are unsaturated".

It is clear that the truth of these sentences does not require that Descartes or Frege have used the English expressions quoted in (4) and (5) in order to express their views. Indeed, expansions of (4) and (5) where it is explicitly indicated that Descartes and Frege have used languages other than English in order to express their views are not semantically odd, which they should be, if the truth of (4) and (5) really required that Descartes and Frege have expressed their views by using the English expressions that (4) and (5) quote:

(4a) In a Latin work that has become famous among philosophers, Descartes said that man "is a thinking substance".

(5a) In a German paper that has often been cited by modern semanticists, Frege said that predicate expressions "are unsaturated".

On C\&L's theory, however, the truth of (4) and (5) does require that Descartes and Frege have used the English expressions therein quoted in order to express their reported views. For, on C\&L's theory, the semantic representations of (4) and (5) are (4-D) and (5-D), respectively:

(4-D) $\exists u(\operatorname{Said}(\mathrm{d}, u) \& \operatorname{SS}(u$, that $) \& \operatorname{ST}(u$, these $))$. Man is a thinking substance

(5-D) $\exists u(\operatorname{Said}(\mathrm{f}, u) \& \mathrm{SS}(u$, that $) \& \mathrm{ST}(u$, these $))$. Predicate expressions are unsaturated.

And these cannot be true unless Descartes and Frege have sametokened, at least in part, the English expressions therein demonstrated. Since, therefore, the truth of (4) and (5) does not require that the quoted subjects have ever used expressions that are replicas of English expressions, whereas the truth of (4-D) and (5-D) does impose such a requirement, it follows that (4-D) and (5-D) cannot be, as C\&L's theory predicts, correct semantic representations of (4) and (5), respectively. 
In a short paper purporting to reply to my arguments (Cappelen \& Lepore 1998), C\&L characterize the examples to which this argument appeals as "mixed quotes in which the direct quoted part is a translation of the words used in the quoted utterances", and declare themselves "prejudiced in favor of a unified account" of mixed quotation that would encompass both these "translational" mixed quotes and the "standard" mixed quotes studied in their original paper (all quotations from Cappelen \& Lepore 1998: 665; notice that no distinction between 'standard' and 'non-standard' mixed quotes was employed anywhere in C\&L's original paper, and that no analysis of that distinction is attempted in the text of their reply). At this point one would expect C\&L either to actually propose the "unified account" of mixed quotation in favor of which they say they are predisposed (and which, when available, would cover both 'translational' and 'standard' mixed quotes) or to postpone the construction of such a "unified account" to a future occasion. Astonishingly, however, C\&L do neither of these things, suggesting instead that their original account just is the sought for "unified account". But how could this be, given that their account, by virtue of the sametokening clause it contains, makes obviously incorrect predictions when applied to mixed quotes of the "translational" variety? C\&L's entire answer to that crucial question is that they place "no a priori constraints on what can same-token what" and that, in particular, they "see no principled objection to saying that in some contexts same-tokening can rely on translation" (quotations from Cappelen \& Lepore 1998: 665).

That answer is entirely unsatisfactory, though seeing that it is may require a few more words than it itself contains. The first part of the answer, in which C\&L present themselves as jettisoning all "a priori constraints on what can same-token what", is probably not meant to be taken seriously, and cannot, in any case, be so taken, since some a priori constraints would obviously be part of any account. For example, even C\&L would presumably require that sametokening is not a relation that everything bears to everything else; but the requirement that sametokening is not a relation instantiated by just any pair of objects is certainly an a priori, rather than an a posteriori, constraint on sametokening. Similarly, even C\&L would presumably require that, since the sametokening relation is a particular kind of similarity relation, it must be symmetric rather than asymmetric; but the requirement that the sametokening relation should, qua similarity relation, be symmetric is certainly an a priori, rather than a posteriori, constraint on sametokening, deriving as it does from an a priori, rather than a posteriori, constraint on the notion of similarity. It would seem, then, that C\&L could not really mean what they say when they deny commitment to any a priori constraints. But since they don't say which a priori constraints they like and which they don't, it is best to leave that matter to one side and turn to the remaining, and less insubstantial, part of their answer, 
which is to the effect that their theory can avoid the counterexamples in (4) and (5) by imposing the (presumably, a posteriori) constraint that "in some contexts same-tokening can rely on translation".

The first thing to notice about this 'constraint' is that, whether or not it achieves its purpose, it involves a radical, and unacknowledged, change in C\&L's conception of the sametokening relation. The notion of sametokening originally employed by $\mathrm{C} \& \mathrm{~L}$ was meant to be a refined version of the central idea of Davidson's analysis of direct quotation - the idea, namely, that, in direct quotation, what the quoting speaker does is, on the one hand, to demonstratively refer to an utterance and, on the other hand, to claim that the quoted speaker produced an utterance with the same shape as the utterance demonstratively referred to (notice that, in his reaction to a recycled version of C\&L's original paper, Davidson considers the, according to him, "unimportant" question whether the refinements suggested by C\&L would really be required, and explicitly denies that they would, pointing out that the thought that they would relies on a misunderstanding of his conception of the notion of shape; see Davidson 1999: 101). Now, if the notion of sametokening is to be construed, as C\&L were originally supposing, along these Davidsonian lines - namely, as a relation that two utterances have when they have the same shape -, then it is clear that (4) and (5) are inescapable counterexamples to C\&L's analysis of mixed quotation. For, as we have seen, the truth of (4) and (5) is consistent with Descartes' and Frege's having used only Latin and only German expressions, respectively, in order to formulate their views. And since there are no Latin and no German expressions with the same content and the same shape as the English expressions quoted in (4) and (5), it follows that the truth of (4) and (5) is consistent with neither Descartes' nor Frege's having ever sametokened those English expressions, contrary to what C\&L's analysis predicts. If the original understanding of the sametokening relation remains in force, then, C\&L's analysis is as clearly mistaken as an analysis could be.

C\&L's reaction to this situation has the merit of not retreating to the false claim that the truth of (4) and (5) does require Descartes and Frege to have used English in order to express their views. It does not, however, have the merit of explicitly acknowledging that their proposed way of dealing with the situation involves not a reformulation but a rejection of their original understanding of the sametokening relation. For, their proposed way of dealing with the situation consists in saying that "same-tokening can rely on translation" - in other words, that Descartes and Frege may well have used only Latin and only German expressions, respectively, in order to formulate the views truthfully reported in (4) and (5), but that this can be made consistent with the idea that their expressions sametoken the English expressions quoted in (4) and (5), if one assumes that expressions belonging to two different languages are to be counted as sametokening each other as long as they are 
translations of each other. That assumption, however, whether or not it leads to an acceptable new theory, amounts to a complete rejection of the original understanding of the sametokening relation: On anyone's account, expressions from two different languages that are translations of each other are expressions that have the same content even though they may have completely different shapes. Given, then, that translation is a process that aims at contentpreservation rather than shape-preservation, and given, on the other hand, that it is shape-preservation rather than content-preservation that was the defining characteristic of the original account of the sametokening relation deriving from Davidson, C\&L's reaction to the problem posed by (4) and (5) involves using a notion of sametokening that is not merely different from but actually opposite to the notion of sametokening with which they have been working. Instead, therefore, of misleadingly suggesting that their original account of mixed quotation can deal with (4) and (5) as it stands, they should simply acknowledge that (4) and (5) compel them to put forward a new account of mixed quotation, and that the particular account that they have chosen to put forward (whether as a substitute for or as a supplement to the old one) introduces a notion of sametokening that is the exact opposite of the notion they have been using.

The next question is whether the new account is less unsuccessful than the old one. Unfortunately, it is not, though for different reasons. Let us assume, as C\&L now propose, that sametokening is a relation that holds between two expressions when they are 'translations' of each other - that is, when their content is the same, even though their shapes may be wildly different. Of course, anyone expecting that a definition of the sametokening relation should be consistent with generally held assumptions about the distinction between expression types and expression tokens would find the new definition unacceptable, since, interpreted as a way of recapturing the type/token distinction, it has obviously absurd implications (it implies, for example, that a token of the English word "day" and a token of the French word "jour" are tokens of the same word, simply because they happen to have the same content, or that a token of the word "pianoforte" and a token of the word "fortepiano" are tokens of the same word, simply because they both happen to refer to the same musical instrument.) Nevertheless, since C\&L would have probably disowned by now any commitment to mean by the term 'sametokening' what everyone else would expect that term to mean (this is, perhaps, what they were really gesturing at by expressing their dislike of all 'a priori constraints' on sametokening), it would be unfair to fault their new account on these grounds. The real problem with the new account is that, by proposing an understanding of sametokening based on the notion of translation - and so, exclusively on content-preservation, rather than on shapepreservation - the new account makes the sametokening relation 
indistinguishable from the samesaying relation, contrary to what C\&L's general views about quotation explicitly require.

Recall that, on C\&L's original exposition of their views, direct quotation, indirect quotation and mixed quotation were different phenomena requiring distinct accounts, and that the accounts proposed by $\mathrm{C} \& \mathrm{~L}$ were aiming to respect that distinctness requirement by analyzing direct quotation exclusively in terms of the notion of sametokening, indirect quotation exclusively in terms of the notion of samesaying, and mixed quotation in terms of a combination of the notions of sametokening and of samesaying. Clearly, the distinctness requirement could not be coherently fulfilled if sametokening and samesaying turned out to be the very same notion. But if, as $\mathrm{C} \& \mathrm{~L}$ now propose, sametokening is a relation that holds between two utterances when they are 'translations' of each other-that is, when they have the same content, irrespective of their possible differences in shape-, then sametokening cannot be distinct from samesaying. For, the notion of samesaying that C\&L claimed they were assuming is the notion of samesaying introduced in Davidson's (1968) analysis of indirect quotation. And the notion of samesaying introduced in Davidson's analysis of indirect quotation just is the notion of two utterances' having the same content (and, being, in that sense, 'translations' of each other) irrespective of their possible differences in shape. As Davidson quite explicitly puts it at one point, the claim that, in indirect quotation, the quoting speaker asserts that a demonstratively indicated utterance samesays an utterance produced by the quoted speaker, is equivalent to the claim that, in indirect quotation, the quoting speaker asserts that a demonstratively indicated utterance has "the same content as ('translates')" an utterance produced by the quoted speaker (Davidson 1976: 39). If, therefore, the new sametokening relation proposed by C\&L is what they say it is - namely, a relation holding between two utterances when they are translations of each other-, then the notion of sametokening simply is the very same notion as the notion of samesaying they were presenting themselves as assuming. But - and this is the crucial point - if the notions of sametokening and samesaying are the very same notion, then their own analytical requirements are massively and irreparably violated: not only must their analysis of mixed quotation now be recognized to have been multiply mistaken (first because either its samesaying or its sametokening clause becomes redundant, and secondly because, whichever of these clauses is dropped, the analysis fails to properly distinguish mixed quotation from either direct quotation or indirect quotation), but the very possibility of distinguishing direct from indirect quotation itself evaporates (if sametokening and samesaying are the very same thing, it is impossible for an analysis of direct quotation in terms of sametokening to be saying anything distinct from an analysis of indirect quotation in terms of samesaying). 
I conclude that C\&L's attempted defense of their analysis against the first of the two arguments developed in Tsohatzidis (1998) leaves them in a position noticeably worse than the position they originally occupied. Had they stood by their initial conception of the sametokening relation (which they had derived from Davidson), they would have to concede that their analysis of mixed quotation is inadequate, but they could retain the analyses of direct and of indirect quotation that they inherit from Davidson. By changing their conception of sametokening beyond all recognition, however, they succeed in arriving at a situation where, contrary to their own requirements, they can properly account neither for direct quotation, nor for indirect quotation, nor for mixed quotation.

\section{The samesaying problem}

The second of the two arguments presented in Tsohatzidis (1998) against C\&L's hybrid theory shows that there are instances of mixed question that, though they may be taken to satisfy the sametokening clause of C\&L's analysis, cannot be taken to satisfy the samesaying clause. Suppose that, having misperceived the color of a rose that is, in fact, white, Alice has incorrectly asserted, pointing to the rose in question, "This is a red rose"; and that, having misidentified a woman who is, in fact, the Queen of England, Alice has incorrectly asserted, pointing to the woman in question, "That woman is the Queen of England's mother". Wishing to emphasize how mistaken Alice has been in her statements, a speaker then produces the following reports:

(6) Alice said that this white rose "is a red rose".

(7) Alice said that the Queen of England "is the Queen of England's mother".

It is clear that in order for these sentences to be true, it is not necessary that Alice should have expressed the contradictory view that a white rose is a red rose, or the contradictory view that the Queen of England is the Queen of England's mother (after all, Alice was just mistaken, not demented). Indeed, expansions of (6) and (7) where it is explicitly indicated that Alice did not express any such contradictory views are not semantically odd, as they should be, if the truth of (6) and (7) really required Alice to have expressed the contradictory views in question:

(6a) Alice said that this white rose "is a red rose" - without, of course, realizing, let alone claiming, that it $i s$ white. 
(7a) Alice said that the Queen of England "is the Queen of England's mother" - without, of course, realizing, let alone, claiming, that she is the Queen of England.

However, the analyses of (6) and (7) that C\&L's theory of mixed quotation provides do require Alice to have expressed precisely those contradictory views. For, on C\&L's theory, the semantic representations of (6) and (7) are (6D) and (7-D), respectively:

(6-D) $\exists u(\operatorname{Said}(\mathrm{a}, u) \& \mathrm{SS}(u$, that $) \& \mathrm{ST}(u$, these $))$. This white rose is a red rose.

(7-D) $\exists u(\operatorname{Said}(\mathrm{a}, u) \& \mathrm{SS}(u$, that) \& $\mathrm{ST}(u$, these)). The Queen of England is the Queen of England's mother.

And these could not have been true unless Alice had samesaid (that is, had uttered sentences identical in content with) the explicitly contradictory sentences "This white rose is a red rose" and "The Queen of England is the Queen of England's mother". Since, therefore, the truth of (6) and (7) does not require Alice's commitment to any explicit contradictions, whereas the truth of (6-D) and (7-D) does require such a commitment, it follows that (6-D) and (7D) cannot be, as C\&L suppose, correct semantic representations of (6) and (7), respectively.

In the short paper purporting to reply to my arguments, $C \& L$ simply say that this argument relies on a "misreading" of their original paper. The argument, they note, "assumes that we think that the samesay relation holds between all and only utterances that are 'identical in content". But, they point out, "We don't." (All quotations from Cappelen \& Lepore 1998: 665.) Since this is all that C\&L say in reply, someone might wonder why they didn't take the trouble to even briefly enlighten their readers as to what the conception of samesaying assumed in their original paper really is, if it is not a conception based on sameness of content. The answer to that question is that they couldn't possibly provide such enlightenment, since the conception of samesaying assumed in their original paper simply is the conception according to which two utterances samesay each other just in case they have the same content. More specifically, the only thing that C\&L's original paper says about samesaying is that its authors rely on the understanding of that notion provided in Davidson's account of indirect quotation (indeed, C\&L make it a point to emphasize that they are merely interested in showing how Davidson's account of indirect quotation, assuming it to be correct, can be "exploited" in their own account of mixed quotation, but disavow any intention "to engage in an evaluation" of it; see Cappelen \& Lepore 1997a: 442). However, Davidson's account of indirect quotation explicitly defines the samesaying relation as a 
relation holding between utterances when they have the same content (as we have already seen, utterances samesaying each other are, according to Davidson, all and only utterances that have "the same content" (Davidson 1976: 39), or, as he also puts it in the paper that C\&L cite, that "match in content" (Davidson 1968: 145)). Consequently, anyone reading C\&L's original paper and wishing to suppose that the notion of samesaying they employ is not meaningless has no other option but to suppose that it has the meaning that Davidson stipulated for it. In which case, of course, employing Davidson's interpretation of samesaying in reading their original paper not only does not constitute a "misreading" of that paper but rather constitutes the only course of action capable of avoiding the hypothesis that the paper employs the notion of samesaying without giving it any meaning.

Of course, that particular interpretation of C\&L's paper might be taken to have been unduly charitable, if C\&L's real position on the notion of samesaying turned out to be that that notion cannot, in fact, be given any substantive meaning. And, unfortunately, this is what their real position appears to be, if one is to judge from their reply. For their reply cites, purportedly as a clue to their real position on the samesaying relation, a different paper of theirs published after the one I was criticizing (Cappelen \& Lepore 1997b), in which, along with repudiating certain theses about the goals of semantics held, according to them, both by Davidson and by virtually every other contemporary philosopher of language, they explicitly abandon Davidson's account of indirect quotation on the grounds that it imposes "a priori constraints on what can samesay what" (Cappelen \& Lepore 1997b: 291) and avoids "closely attending to our actual practice of indirect reporting" (Cappelen \& Lepore 1997b: 293). Now, the various claims of that later papernone of which had been used in the earlier one - have been extensively and effectively criticized in the literature (see Reimer 1998 and, especially, Richard 1998), but these criticisms need not be invoked in the present connection. What does need to be noticed is simply that, even if all of C\&L's later antiDavidsonian claims were correct, no alternative definition of the samesaying relation would be derivable from them. For, obviously, delivering sermons against 'a priori constraints on samesaying' and thereby rejecting Davidson's account of indirect quotation does not amount to actually proposing any positive account of indirect quotation or of samesaying. And, in the later paper, C\&L make it perfectly clear that they simply have no positive account to offer: from their criticisms of Davidson's account of indirect quotation, they tell us, "no positive theory of indirect quotation follows" (Cappelen \& Lepore 1997b: 291 , italics original). But if no positive theory of indirect quotation follows, no positive characterization of samesaying can follow either; indeed, the only characterization of samesaying that, in the context of C\&L's later paper, becomes possible is the following completely vacuous one: samesaying is that 
relation between reported utterances and reporting clauses which is such that, if we knew what it is (which we don't), we would know when a sentence containing an indirect quotation is true and when it is false. But this is not an alternative to Davidson's or to anyone else's account of samesaying or of indirect quotation. It is just a refusal to commit oneself to any substantive account. And the refusal to undertake substantive commitments can hardly be construed as a way of fulfilling substantive commitments: if reference to the samesaying relation really gives, as C\&L's original paper was claiming, the truth conditions of sentences containing indirect quotations, then the samesaying relation could not without circularity be defined, as C\&L's later paper suggests, as the relation which is such that, if we knew what it is, we would know when a sentence containing an indirect quotation is true and when it is false. It seems, then, that, instead of protesting that they have been 'misread', C\&L should simply acknowledge that they are facing a dilemma: either to rely on Davidson's definition of samesaying, and draw the negative implications that that reliance turns out to have on their analysis of mixed quotation, or to claim that no substantive definition of samesaying can possibly be given, in which case, of course, they would have been left with no substantive analysis to defend.

My conclusion is that C\&L's reaction to the second of two arguments developed in Tsohatzidis (1998) makes things worse for them than they already were. Had they remained faithful to the content-based understanding of samesaying that a charitable interpretation of their original text demands, they could at least retain the account of indirect quotation that they inherit from Davidson, though they would obviously have to abandon their account of mixed quotation (since, in view of the proposed counterexamples, retaining that account would require endorsing the preposterous claim that contradictory and non-contradictory sentences have the same content). By effectively refusing to give any interpretation to the samesaying clauses that their analyses contain, however, they remain with no real analysis of either mixed or indirect quotation (and, a fortiori, with no means of differentiating either of these phenomena from the phenomenon of direct quotation).

\section{The combined problem}

A question that was not raised in Tsohatzidis (1998) is whether, apart from cases of mixed quotation like those so far considered - that is, cases where the one or the other, but not both, of the clauses introduced by C\&L, fails to be satisfied-there are cases with respect to which the sametokening and samesaying clauses of C\&L's analysis would simultaneously fail to be 
satisfied, and which would therefore provide independent evidence against the alleged necessity of these clauses. We will now see that such cases exist, too.

Consider the following dialogues between John and his sister Jane, where Jane appeals to her mother's authority in order to dispute the correctness of her brother's use of certain referring expressions:

(8) John. Let's drink this marvelous apple juice. Jane. Mom said that "this marvelous apple juice" is whiskey.

(9) John. Would you like me to play that nice violin for you? Jane. Mom said that "that nice violin" is a cello.

On C\&L's analysis, the semantic representations of Jane's utterances in these dialogues would be, respectively, the following:

(8-D) $\exists u(\operatorname{Said}(\mathrm{m}, u) \& \mathrm{SS}(u$, that $) \& \mathrm{ST}(u$, these)). This marvelous apple juice is whiskey.

(9-D) $\exists u(\operatorname{Said}(\mathrm{m}, u) \& \mathrm{SS}(u$, that $) \& \mathrm{ST}(u$, these $))$. That nice violin is a cello.

It is clear that taking these representations to be correct requires accepting that Jane's utterances in (8) and (9) could not be true unless it was Jane's mother who had both samesaid and at least partly sametokened the utterances demonstratively referred to in (8-D) and (9-D). It is equally clear, however, that the truth of Jane's utterances in (8) and (9) does not require her mother to have either samesaid or even partly sametokened the utterances demonstratively referred to in (8-D) and (9-D). Specifically, although Jane's utterances in (8) and (9) may be meant to suggest that her brother has inadvertently committed himself to the obviously false views that apple juice is whiskey and that violins are cellos, the truth of Jane's utterances certainly does not require that her mother has committed herself to any such views, since it does not require that her mother has produced utterances identical in content with the obviously false utterances "This marvelous apple juice is whiskey" and "That nice violin is a cello". Indeed, Jane could without any semantic oddity expand her utterances in (8) and (9) by explicitly denying that her mother has ever produced utterances identical in content with those obviously false utterances. And this suffices to show that it is not a condition on the truth of Jane's claims in (8) and (9) that her mother has samesaid those obviously false utterances. But neither does the truth of Jane's utterances in (8) and (9) require her mother to have produced any tokens of the expression "this marvelous apple juice" (as, according to Jane, her brother did while attempting to refer to what was, in fact, whiskey), or any tokens of the expression "that nice violin" (as, according to Jane, her brother did while attempting to refer to 
what was, in fact, a cello). Indeed, Jane could without any semantic oddity expand her utterances in (8) and (9) by stating what is anyway contextually obvious, namely, that it is only her brother's mistaken use of these referring expressions that she meant to be quoting while speaking about her mother. And this suffices to show that it is not a condition on the truth of Jane's utterances in (8) and (9) that her mother has sametokened these referring expressions. But if the truth of Jane's utterances in (8) and (9) does not require Jane's mother to have produced any utterances that either samesay or sametoken the utterances demonstratively referred to in (8-D) and (9-D), it follows that (8) and (9) are instances of mixed quotation with respect to which the samesaying and the sametokening clauses of C\&L's analysis are simultaneously not satisfied. And these instances, of course, provide independent evidence against the claim that these clauses specify necessary conditions on mixed quotation.

It is important to notice that nothing in the above argument excludes the possibility that there might be contexts, different from the one suggested by the dialogues in (8) and (9), relative to which the truth of Jane's utterances would require her mother to have both samesaid and at least partly sametokened the utterances demonstratively referred to in (8-D) and (9-D) - one such context, for example, could (given certain assumptions) be the context where Jane responds to John exactly as she does above, but where John's utterance is neither the one figuring in (8) nor the one figuring in (9) but rather the utterance Tell me, Jane, have you noticed anything recently that has made you think that mom is becoming crazy?. That possibility, however, far from comforting $\mathrm{C} \& \mathrm{~L}$ analysis, would reveal a deep flaw in its orientation. For, the fact that seemingly unambiguous utterances such as Jane's cannot have truth conditions that are stable across these and many other conversational environments suggests that, in each instance of mixed quotation, the question who is being quoted in that instance cannot have a context-invariable answer. And since the truth conditions for mixed quotation that C\&L propose assume that, in each instance of mixed quotation, that question does have a contextinvariable answer, their analysis can justifiably be taken to be no less misguided, and no more secure against potential counterexamples, than an analysis that would attempt to attribute to each sentence containing an indexical a context-invariable truth-condition.

\section{The problem of sufficiency}

Though it should be clear by now that neither the samesaying nor the sametokening clauses of C\&L's analysis specify necessary conditions on mixed quotation, the arguments to this effect developed above and in Tsohatzidis (1998) have left open the question whether the two clauses, 
together with the trivially required clause about utterance-production that precedes them, jointly specify sufficient conditions for mixed quotation. We are now going to see that they do not specify sufficient conditions, either.

To begin with a problem that, though real enough, would not be unmanageable, note that the kinds of representations C\&L use do not invariably equip them with a fully unambiguous format for the expression of their claims about mixed quotation. For example, the following sentences are obviously not semantically equivalent, and one should accordingly expect an adequate theory of mixed quotation to provide non-equivalent semantic representations for them.

(10a) Ann said that "books" cost a lot.

(10b) Ann said that books "cost" a lot.

(10c) Ann said that books cost "a lot".

(10d) Ann said that "books cost" a lot.

(10e) Ann said that books "cost a lot".

However, all these sentences would receive, given the formalism C\&L employ, exactly the same semantic representation, namely, (10-D):

(10-D) $\quad \exists u(\operatorname{Said}(\mathrm{a}, u) \& \operatorname{SS}(u$, that $) \& \mathrm{ST}(u$, these $))$. Books cost a lot.

For, what (10-D) says is simply that Mary produced an utterance that, on the one hand, samesays, and, on the other hand, at least partly sametokens, the utterance "Books cost a lot". And if this is what any of the sentences in (10a)(10e) means, then it is what they all mean. Consequently, accepted as it stands, C\&L formalism would have the effect of representing as semantically equivalent sentences that are not, in fact, semantically equivalent.

Now, this particular problem could be easily overcome. To make the formalism more discriminating, one should enrich it with a bracketing and coindexation system that would make it possible to unambiguously express, in each proposed representation, which demonstrating elements are supposed to refer to which demonstrated elements, and would thus associate with semantically non-equivalent sentences like those in (10a)-(10d) semantically non-equivalent proposed representations like those in (10a-D)-(10e-D), respectively:

(10a-D) $\exists u\left(\operatorname{Said}(\mathrm{a}, u) \& \mathrm{SS}(u\right.$, that $) \& \mathrm{ST}\left(u\right.$, these $\left.\left.\mathrm{i}_{\mathrm{i}}\right)\right)$. [Books] $]_{\mathrm{i}}$ cost a lot. (10b-D) $\exists u\left(\operatorname{Said}(\mathrm{a}, u) \& \mathrm{SS}(u\right.$, that $) \& \mathrm{ST}\left(u\right.$, these $\left.\left._{\mathrm{i}}\right)\right)$. Books [cost $]_{\mathrm{i}}$ a lot.

(10c-D) $\quad \exists u\left(\operatorname{Said}(\mathrm{a}, u) \& \mathrm{SS}(u\right.$, that $) \& \mathrm{ST}\left(u\right.$, these $\left.\left.\mathrm{i}_{\mathrm{i}}\right)\right)$. Books cost [a lot $]_{\mathrm{i}}$.

(10d-D) $\quad \exists u\left(\operatorname{Said}(\mathrm{a}, u) \& \mathrm{SS}(u\right.$, that $) \& \mathrm{ST}\left(u\right.$, these $\left.\left.\mathrm{i}_{\mathrm{i}}\right)\right)$. [Books cost] ${ }_{\mathrm{i}}$ a lot.

(10e-D) $\exists u\left(\operatorname{Said}(\mathrm{a}, u) \& \mathrm{SS}(u\right.$, that $) \& \mathrm{ST}\left(u\right.$, these $\left.\left.\mathrm{i}_{\mathrm{i}}\right)\right)$. Books [cost a lot $]_{\mathrm{i}}$. 
There is, however, a further, and this time quite serious, problem for C\&L's analysis that cannot be overcome by any such notational maneuvers. The problem is that only some and not all arrangements of quotational devices in the complement clause of a mixed quotation are attestable, and that any theory which, like C\&L's, is completely unable to predict which arrangements are attestable and which are not fails to provide sufficient conditions for mixed quotation.

For example, any adequate theory (and, of course, any theory which, like C\&L's, is rich in exhortations about "closely attending to our actual practice" of quotation) should be in a position to predict that (11) and (12) represent attestable instances of mixed quotation whereas (13) does not, or that (14) and (15) represent attestable instances of mixed quotations whereas (16) does not:

(11) Mary said that John is "fed up" with music.

(12) Mary said that John is fed up "with music".

(13) * Mary said that "John is fed" up with music.

(14) Mary said that "whom John killed" is the big question.

(15) Mary said that whom John killed "is the big question".

(16) * Mary said that whom John "killed is the" big question.

C\&L's theory, however, is not capable of delivering these predictions. What it falsely predicts, instead, is that all of the above instances of mixed quotation are equally attestable, since, as far as the theory is concerned, no restrictions of any sort are stipulated that would allow one to distinguish between permissible and impermissible arrangements of quotational devices in the complement clause of a mixed quotation (to put it in the theory's terminology, no restrictions of any sort are stipulated that would allow one to distinguish between 'parts' of the complement clause that would and 'parts' of the complement clause that would not be permissible terms of the hypothesized sametokening relation).

Clearly, this problem cannot be overcome by just equipping the theory with the bracketing and co-indexation system envisaged above; indeed, such a system would merely help re-expressing the problem more precisely - namely, as the problem of finding out why some but not all of the theoretically possible co-indexations correspond to attestable as opposed to unattestable instances of mixed quotation. It seems, then, that C\&L's theory must be taken to simply fail to specify sufficient conditions for mixed quotation unless there is an obvious restriction (so obvious, in fact, that - we must suppose - C\&L have not even bothered to state it explicitly) determining which co-indexations correspond to attestable instances and which to unacceptable ones. And the only restriction that would be a plausible candidate for obviousness is, of course, a restriction 
to the effect that attestable instances are those in which the quoted material in the complement clause of a mixed quotation is a syntactic constituent, whereas unattestable instances are those in which the quoted material in the complement clause of a mixed question is not a syntactic constituent (thus, the asterisked examples above would be unattestable because the quotation marks they contain do not isolate syntactic constituents, whereas the un-asterisked ones would be attestable because the quotation marks they contain do isolate syntactic constituents). Unfortunately, however, obvious solutions are not always correct ones, and the solution just suggested is a case in point. For there are plenty of routinely attestable instances of mixed quotation where the quoted expression in the complement clause is not a syntactic constituent. In the exchanges below, for example, the expressions "critics liked" and "thieves have stolen" are certainly not syntactic constituents, and yet there is nothing extraordinary about the mixed quotations employed:

(17) $A$. What did John say about the book?

$B$. He said that "critics liked" it.

(18) $A$. What did John say about the box?

$B$. He said that "thieves have stolen" it.

The situation, then, is one in which there appear to be both quite potent and quite unobvious reasons why some instances of mixed quotation are attestable and some others unattestable. And since there is nothing in C\&L's analysis that could help one to even suspect what these reasons are, the analysis can certainly not be supposed to provide sufficient conditions for mixed quotation.

\section{Conclusion}

We have just seen that the samesaying and sametokening clauses of C\&L's analysis, together with the trivially required clause about utterance-production that precedes them, do not jointly specify sufficient conditions for mixed quotation; and we had already seen that, for at least three different reasons, the samesaying and sametokening clauses do not specify individually necessary conditions either. Combining these two results, it would not, I suppose, be unfair to conclude that C\&L's actual contribution to the study of the phenomenon of mixed quotation amounts to a mere reminder that the phenomenon exists ${ }^{1}$. 


\section{Note}

${ }^{1}$ The brief restatement of their account of mixed quotation that Cappelen \& Lepore include in their contribution to the present volume gives me no grounds to modify this judgment: the samesaying and the sametokening problems remain persistently unresolved; a solution to the sufficiency problem is glaringly absent; and the combined problem cannot be avoided by appeal to C\&L's distinction between scare-quoting and mixed-quoting, if only because that distinction (whose import is, of course, no clearer than the metaphor of 'distancing' on which it relies) is explicitly acknowledged by $\mathrm{C} \& \mathrm{~L}$ to be non-semantic, and so cannot underwrite an ambiguity claim that would be required for an effective defense.

I would like to thank Charis-Olga Papadopoulou and Philippe De Brabanter for their comments on an earlier version of the present paper. The usual disclaimers apply.

\section{References}

Cappelen, H. \& Lepore, E. 1997a. "Varieties of quotation”. Mind 106: 429-450.

Cappelen, H. \& Lepore, E. 1997b. “On an alleged connection between indirect speech and the theory of meaning". Mind and Language 12: 278-296.

Cappelen, H. \& E. Lepore 1998. "Reply to Tsohatzidis". Mind 107: 665-666.

Davidson, D. 1968. "On saying that". Synthese 19: 130-146.

Davidson, D. 1976. "Reply to Foster". In G. Evans \& J. McDowell (eds), Truth and Meaning: Essays in Semantics. Oxford: Clarendon Press, 33-41.

Davidson, D. 1979. “Quotation”. Theory and Decision 11: 27-40.

Davidson, D. 1999. "Reply to Cappelen and Lepore". In U. M. Zeglen (ed), Donald Davidson: Truth, Meaning and Knowledge. London: Routledge, 100-101.

Reimer, M. 1998. "What is meant by 'what is said': a reply to Cappelen and Lepore". Mind and Language 13: 598-604.

Richard, M. 1998. "Semantic theory and indirect speech". Mind and Language 13: 605-616.

Tsohatzidis, S. L. 1998. "The hybrid theory of mixed quotation”. Mind 107: 661-664. 